\title{
Animal Models of Temporomandibular Disorder
}

\author{
Ting Xiang ${ }^{1,2}$ \\ Zhuo-Ying Tao ${ }^{3}$ \\ Li-Fan Liao' \\ Shuang Wang ${ }^{2}$ \\ Dong-Yuan Cao (1D \\ 'Key Laboratory of Shaanxi Province for \\ Craniofacial Precision Medicine Research, \\ Research Center of Stomatology, Xi'an \\ Jiaotong University College of \\ Stomatology, Xi'an, Shaanxi, 710004, \\ People's Republic of China; ${ }^{2}$ Department \\ of Orthodontics, Xi'an Jiaotong \\ University College of Stomatology, Xi'an, \\ Shaanxi, 7I0004, People's Republic of \\ China; ${ }^{3}$ Discipline of Oral and \\ Maxillofacial Surgery, Faculty of Dentistry, \\ The University of Hong Kong, Sai Ying \\ Pun, Hong Kong, 999077, People's \\ Republic of China
}

Correspondence: Dong-Yuan Cao

Tel +86-29-87216708

Fax +86-29-87273400

Email dongyuan_cao@hotmail.com

Shuang Wang

Tel +86-13630258962

$\mathrm{Fax}+86-29-87273400$

Email shuangw98@163.com

\begin{abstract}
Temporomandibular disorders (TMD) are a group of diseases in the oral and maxillofacial region that can manifest as acute or chronic persistent pain, affecting millions of people worldwide. Although hundreds of studies have explored mechanisms and treatments underlying TMD, multiple pathogenic factors and diverse clinical manifestations make it still poorly managed. Appropriate animal models are helpful to study the pathogenesis of TMD and explore effective treatment measures. At present, due to the high cost of obtaining large animals, rodents and rabbits are often used to prepare TMD animal models. Over the past decade, various animal models have been intensively developed to understand neurobiological and molecular mechanisms of TMD, and seek effective treatments. Although these models cannot carry out all clinical features, they are valuable in revealing the mechanisms of TMD and creating curative access. Currently, there are multitudinous animal models of TMD research. They can be constructed in different means and summarized into four ways according to the various causes and symptoms, including chemical induction (intra-articular injection of ovalbumin, collagenase, formalin, vascular endothelial growth factor, intramuscular injection of complete Freund's adjuvant, etc.), mechanical stress stimulation (passive mouth opening, change of chewing load), surgical operation (partial disc resection, joint disc perforation) and psychological stress induction. Here, we summarize and discuss different approaches of animal models for determining neurophysiological and mechanical mechanisms of TMD and assess their advantages and limitations, respectively.
\end{abstract}

Keywords: temporomandibular disorder, mechanism, animal model, treatment

\section{Introduction}

Temporomandibular disorders (TMD) are a group of diseases involving the masticatory muscles, temporomandibular joint (TMJ), associated structures, and are characterized by orofacial pain, joint sounds and restricted mandibular movement. TMD is one of the major causes of non-dental pain in the orofacial region. Besides, TMD commonly occurs in young and middle-aged people, with the highest prevalence and consultation rate at the age of 20-30 years. Additionally, TMD has a higher prevalence in women, ${ }^{1}$ especially those in childbearing age. $^{2}$ It has been shown that the prevalence of TMD varies from $21.1 \%$ to $73.3 \%$, and painful signs or symptoms range from $3.4 \%$ to $65.7 \%$, while the frequency of non-painful TMD signs or symptoms varies from $3.1 \%$ to $40.8 \%{ }^{3}$ However, TMD is poorly managed in the dental clinical practice due to the multifactorial etiology and complicated clinical manifestations, yet the effective mechanism-based therapy for TMD is still under investigation.

\section{Characteristics of TMD Clinical Classification of TMD}

TMD can be further classified into four types including temporomandibular joint disorders, masticatory muscle disorders, headache disorders and disorders affecting 
associated structures. ${ }^{4}$ TMJ disorders include joint pain such as arthralgia and arthritis, joint disorders as disc disorders, degenerative joint disease, systemic arthritides, osteochondritis dissecans, osteonecrosis, neoplasm and synovial chondromatosis, fractures, congenital or developmental disorders. Masticatory muscle disorders, accounting for a large proportion of TMD, mainly include myofascial pain, myositis, muscle spasm, unclassified localized myalgia. Patients with myofascial pain often show masseter muscle stiffness and pain, difficulty in movement, etc. In addition, some patients suffer from headache attributed to TMD. TMD symptoms can also behave in some associated structures, such as coronoid hyperplasia. The symptoms of TMD like pain, psychological discomfort, physical disability and limitation of mandibular movements can become chronic and then impair the quality of patients' lives. ${ }^{5}$ Specifically, patients can present with any or all of the following signs: clicking, popping, or crepitus of the TMJ on any of its movements with or without locking of the joint, pain in the TMJ or masticatory muscles, which may radiate to local or distant structures. ${ }^{6}$ Moreover, symptoms are often related to jaw movements and pain in the masseter, preauricular, or temple region, varying from mild discomfort to debilitating pain, including limitations of jaw function.

According to the affected area, TMD can be divided into articular (within the joint) or non-articular (involving the surrounding musculature) disorder, respectively. ${ }^{7}$ The articular disorder occurs due to an altered balance of anabolic and catabolic cytokines, and this imbalance brings about an inflammatory circumstance, which leads to oxidative stress, free radicals, and eventually joint damage. ${ }^{8}$ The most common articular cause of TMD is articular disc displacement involving the condyle-disc relationship, ${ }^{9}$ which may be secondary to osteoarthritis (OA), trauma, infectious arthritis, prior surgery, gout or pseudogout (crystal-arthropathies), rheumatoid arthritis (RA), psoriatic arthritis and ankylosing spondylitis. However, more than $50 \%$ of TMD patients suffer from myofascial pain. Most patients with non-articular disorder present myofascial pain centralized on the muscles of mastication, and radiated to the ears, neck and head, and even accompanied by some chronic conditions, such as muscle strain and myopathies. ${ }^{7}$

\section{Etiology of TMD}

However, the etiology of TMD is multifactorial, as evidenced by the combination of psychological, physiological, structural, postural and genetic factors. ${ }^{10}$ Nowadays, with the study of the etiology of TMD, the multifactorial pathogenic theory and the bio-psycho-social medical model have been widely acknowledged. ${ }^{11}$ Moreover, the clinical characteristics of TMD are so various that it is no longer considered as a singly local disorder but the result of diverse risk determinants. Despite the factors involved in the etiology of TMD are numerous and complex, they are concluded into four categories: (1) Inflammatory factors such as inflammation of the masticatory muscles including masseter and temporal muscles, acute or chronic synovial inflammation of the TMJ; ${ }^{12}$ (2) Occlusal factors like high cusps, excessive wear of teeth, missing molars, poor restorations, low distance between jaws, etc. Disorders of occlusal relationship can disrupt the functional balance between joint internal structures; ${ }^{13}$ (3) Trauma and mechanical factors involving acute trauma such as being hit by external force, biting hard objects, as well as chewing hard food, teeth grinding at night, and unilateral chewing habits, etc. ${ }^{14}$ These factors may cause joint contusion or strain, dysfunction of masticatory muscles; (4) Psychological factors including stress, anxiety, tension and other psychological factors can increase the incidence of pain symptoms, aggravate or prolong the duration of pain symptoms. ${ }^{15}$

\section{Diagnosis of TMD}

In order to better understand the prevalence, incidence, and other characteristics of TMD, integrate the diagnostic methods for TMD and seek effective treatments, the Diagnostic Criteria for TMD (DC/TMD) has been widely employed in both clinical and research settings. ${ }^{4}$ In the early 1990s, pioneers first proposed the TMD dual-axis diagnostic criteria the Research Diagnostic Criteria for TMD (RDC/TMD), that is, to comprehensively evaluate patients with TMD from two aspects involving the body axis and the psychological axis. In the following two decades, after achieving more reliable and valid revisions, the newly commended DC/TMD has been provided. ${ }^{16}$ The implement consists of two axes: Axis I, focusing on the physical profiles, is a means for clinical examination, in which both masticatory muscles and TMJ are assessed; Axis II evaluates psychosocial factors. DC/TMD is recommended not only for research purposes but also in clinical settings in order to screen and test comorbidities and to premeditate the effects of comorbidities when designing fitting treatment for these patients. 


\section{Therapeutics of TMD}

Currently, despite a large number of patients suffer from TMD, the clinical treatments for these patients are largely insufficient since the etiology and pathogenesis of this condition are poorly understood. Generally, treatments for TMD can be summarized into two aspects: conservative and surgical treatments. Medication, physiotherapy, occlusal splints, self-management strategies, and interventions based on cognitive behavioral approaches have been considered conservative treatments. ${ }^{17}$ Simultaneously, surgical treatments involve arthroscopic surgery, arthrocentesis, etc. Compared with surgical approaches, conservative treatments create satisfactory clinical outcomes without invasive damage, while they seem to be ineffective for some patients with severe symptoms. Therefore, the effective therapeutics for TMD is still controversial and urgently needed in the clinical practice, as well as the underlying mechanisms leading to TMD require further investigation.

\section{Neurobiological Mechanisms of TMD}

Given that pain can affect quality of life, and the symptoms can be chronic and difficult to manage, plenty of studies have focused on the mechanisms of pain in TMD patients. In addition to magnetic resonance imaging (MRI) ${ }^{18}$ white matter imaging and structural gray matter imaging techniques have provided an innovative comprehension of structural and functional brain alterations in TMD patients to further investigate the neurophysiological mechanisms. ${ }^{19}$ These studies provide evidence that the dysfunctions of the peripheral and central nervous system occur in TMD-related pain. Peripheral etiological factors, for example, chronic inflammation of TMJ, trauma of the masticatory muscles, and occlusal disorders, play an important role in the development of TMD-pain. Meanwhile, pain in other parts of the body coexisting with TMD-pain suggests that the central nervous system is involved in the occurrence of this kind of pain. ${ }^{20}$ Specifically, classic trigemino-thalamo-cortical system and the lateral and medial pain systems are responsible for the occurrence and development of the abnormal pain perception in TMD patients. Besides, reduced white matter connectivity in the corpus callosum was found in TMD patients through diffusion tensor imaging (DTI), as well as reduced connectivity to the dorsolateral prefrontal cortex (dlPFC), increased connectivity to the frontal polar cortex (FPC). ${ }^{21}$ At the same time, structural gray matter abnormalities and functional MRI findings showed similar changes in FPC. ${ }^{19,22}$
Long-term emotion stress resulting in obvious changes of energy metabolism of masseter muscles in rats may be an important reason for the change of ultrastructure of masseter muscles. ${ }^{23}$ The mechanism of TMD symptoms caused by stress includes both central and peripheral aspects. ${ }^{24}$ As for central mechanism, stress causes the excitability of the hypothalamus-pituitary-adrenal (HPA) axis, increases the secretion of glucocorticoids, hypothalamic adrenergic hormone releasing hormone, and pituitary adrenal stimulating hormone, causing sympathetic nerve excitement, then increased oxygen consumption causes ischemia. In the peripheral, the stress state leads to increased neuromuscular excitability, causing continuous spasm and contraction of the masseter and other masticatory muscles, muscle blood circulation disorders and ischemia, and secondary production of lactic acid, histamine, serotonin, bradykinin, and nerves growth factors, etc. These substances cause local blood vessel dilation, inflammation as well as other phenomena, and ultimately increase the excitability of cell membranes and lower the perception threshold of nociceptors.

Nowadays, there is high comorbidity with functional syndromes such as TMD, fibromyalgia syndrome (FMS) and irritable bowel syndrome (IBS). ${ }^{20}$ Increasing evidence implicates the dysfunction of the central nervous system in pain regulation is associated with TMD. By establishing a comorbid animal model of TMD and FMS, our group found that NMDAR-dependent central sensitization in the spinal dorsal horn and 5-HT-dependent descending facilitation contribute to the development of wide-spreading hyperalgesia in this comorbid pain model. ${ }^{25}$ Subsequently, we found that the down-regulation of 5- $\mathrm{HT}_{2 \mathrm{~A}}$ and $5-\mathrm{HT}_{2 \mathrm{C}}$ receptors in the spinal cord caused dysfunction of the descending pain inhibitory system, which resulted in somatic pain sensitization following orofacial inflammation and stress, suggesting a potential target for the treatment of TMD combined with FMS. ${ }^{26}$ In addition, the release of calcitonin gene-related peptide (CGRP) in TMJ may aggravate other pain disorders in the trigeminal area, leading to the prevalence of comorbidity. ${ }^{27}$ In conclusion, given that TMD is a multifactorial disease, understanding the neurobiological mechanisms of TMD is critical, providing the research direction for clinical treatments.

Animal model of TMD is an essential approach to investigate the pathogenesis of TMD and assess the potential therapeutic interventions since gaining various clinical samples from patients with TMD is difficult. However, the pathogenesis of TMD remains controversial and unclear. In view of the various types of animal models, the 
neurophysiological mechanisms play important roles in the development of TMD.

\section{Animal Models of TMD}

The animal model was defined as

An animal sufficiently similar to a human target group in its physiology or behavior, based on a natural, bred, or experimentally induced characteristic in the animals, and which purpose is to generate knowledge that may be extrapolated to the human target group. ${ }^{28}$

It is an important part of preclinical research and a bridge between basic research and clinical practice. Animal models simulating disease symptoms and pathologies are valuable tools for investigating potential mechanisms of diseases, developing new therapies and predicting effective treatments for diseases. In recent years, there are multitudinous animal models of TMD research. They can be constructed in different means and summarized into the following four ways according to the various causes and symptoms. Here we summarized the TMD animal models and respective physiological and molecular mechanisms according to the different causes of TMD (Table 1 and Figure 1).

For the search strategy and selection criteria, we retrieved studies from the PubMed database up to July 2020, using various combinations of search terms, including temporomandibular disorder, animal model, pain, and neurobiological mechanisms. Original articles, reviews, and other articles were searched, included and reviewed for animal models of TMD. The studies were included based on the criteria: (1) published in the form of an original article; (2) reported the application of different methods to construct a TMD animal model including inflammatory factors, occlusal factors, trauma and mechanical factors, psychological factors, and animal models for TMD comorbid with other diseases; (3) rodents that had not undergone genetic modification or prenatal pressure or sterilization. The search was limited to studies published in English. The studies were excluded: (1) when they appeared to be repeated publications, reviews, letters or comments; (2) when there was no control group in the experiments; (3) and the studies did not use in vivo animal models.

\section{Inflammatory Factors}

Plenty of studies have shown that specific cytokines, antigens and hormones play an essential role in the occurrence and development of TMD. Drugs can be injected through different ways to further induce different types of TMD, like intra-articular or intramuscular injection.

The drugs of intra-articular injection are divided into chemicals, enzymes, hormones and others, providing research methods for $\mathrm{OA}$ and inflammatory TMD. Chemicals include osmic acid, thiotepa, colchicine, nitrogen mustard, iodoacetate and formaldehyde; enzymes include papain, trypsin, hyaluronidase, collagenase and urokinase; hormones include oxytocin, adrenal cortex hormone. Bacteria, zymosan, interleukin-1 (IL-1), tumor necrosis factor (TNF) and transforming growth factor- $\beta 2$ (TGF- $\beta 2)$ are used sometimes. Complete Freund's adjuvant (CFA) contains heat-killed mycobacterium tuberculosis suspended in an oil and saline emulsion. The bacterium is believed to solicit a macrophage immune response that produces acute inflammation. The OA was induced by intra-articular injection of $\mathrm{CFA},{ }^{29}$ which found time-dependent degeneration manner of TMJ cartilage and subchondral bone, suggesting that sustained inflammation is a predisposing factor for TMJ degeneration $^{30}$ and the degeneration in cartilage and subchondral bone happened followed by increased receptor activator of NF-kB ligand (RANKL)/osteoprotegerin (OPG) ratio. This experimental approach provides new insights into the subacute inflammatory processes in the TMJ, enriching our knowledge of the pathogenesis of TMJ-OA and helping design clinically relevant strategies for TMD.

After antigen injection has been recognized as a successful and reliable method for inducing arthritis of the knee joints in rabbits, the antigen-induced arthritis (AIA) in TMJ of the rabbit has been chosen by numerous researchers. ${ }^{31}$ Arthritis was induced with an intra-articular administration of ovalbumin in 10-week-old male New Zealand white rabbits. Antigen-treated joints demonstrated severe arthritis symptoms, involving mononuclear cell infiltration, synovial lining, villous hyperplasia, and pannus formation, which maintain from 5 to 55 days post-operation. ${ }^{32}$ Recently, a large animal model of AIA of the TMJ has been established via the application of bovine serum albumin (BSA) into the pig TMJs. ${ }^{33}$ Compared with the rabbit model, the size, anatomy and mechanical loading in pigs are comparable to those in humans. Imada et $\mathrm{al}^{34}$ injected $1 \%$ collagenase into the cavity of the rat TMJ for 2 weeks and found that the rat condyle cartilage was significantly degenerated, including cartilage fibrosis, proteoglycan loss and clusters of chondrocytes, etc. That is, injection of collagenase was employed to develop the TMJ-OA model out of consideration for operation simplicity, damage controllability and favorable reproducibility, but OA-like lesions appeared later, at least four weeks. Through this model, Li 
Table I Summary of Animal Models for TMD

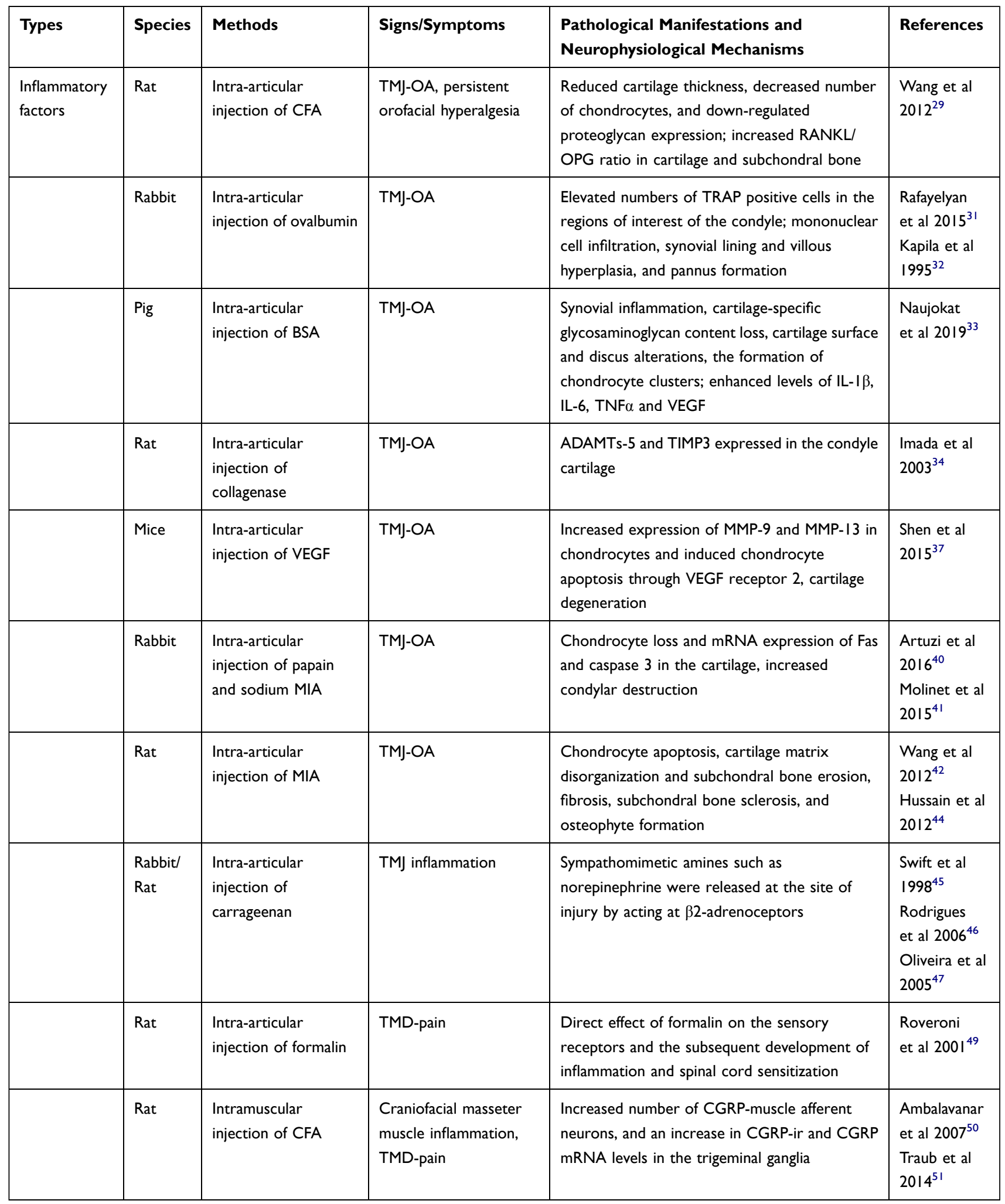

(Continued) 
Table I (Continued).

\begin{tabular}{|c|c|c|c|c|c|}
\hline Types & Species & Methods & Signs/Symptoms & $\begin{array}{l}\text { Pathological Manifestations and } \\
\text { Neurophysiological Mechanisms }\end{array}$ & References \\
\hline \multirow[t]{4}{*}{$\begin{array}{l}\text { Occlusal } \\
\text { factors }\end{array}$} & Rabbit & $\begin{array}{l}\text { Placing metal occlusal } \\
\text { pad on unilateral } \\
\text { molars }\end{array}$ & $\begin{array}{l}\text { TMD-pain, condylar } \\
\text { damage }\end{array}$ & $\begin{array}{l}\text { Increased Fos cells in the TNC; significant } \\
\text { remodeling in the condylar fibrocartilage layers } \\
\text { as manifested by a change in glycosaminoglycan } \\
\text { distribution and a loss of defined cell layers }\end{array}$ & $\begin{array}{l}\text { Henderson } \\
\text { et al } 2015^{54}\end{array}$ \\
\hline & Mice & $\begin{array}{l}\text { Bonding a wire to the } \\
\text { maxillary molar teeth }\end{array}$ & TMJ-OA & $\begin{array}{l}\text { RANKL-induced bone resorption; significant } \\
\text { formation of osteoclasts, upregulation of OPN } \\
\text { and RANKL }\end{array}$ & $\begin{array}{l}\text { Walker et al } \\
2008^{58} \\
\text { Matias et al } \\
2016^{59}\end{array}$ \\
\hline & Rat & ECDO & TMJ-OA & $\begin{array}{l}\text { Degradation in the condylar cartilage } \\
\text { accompanied by an increase in chondrocyte } \\
\text { death and changes in the expression of MMP-3, } \\
\text { MMP-9, TIMP-I and aggrecan in mandibular } \\
\text { condyle cartilage with gender differences }\end{array}$ & $\begin{array}{l}\text { Jiao et al } \\
2009^{60} \\
\text { Wang et al } \\
2010^{62}\end{array}$ \\
\hline & Rat & UAC & TMJ-OA & $\begin{array}{l}\text { Degenerative endochondral ossification; } \\
\text { decreased ratio of hypertrophic cartilage layer, } \\
\text { increased expression of Sox } 9 \text { and ALP, } \\
\text { decreased expression of TGF } \beta 1 \text { and TGF } \beta r 2 \text {, } \\
\text { the expression of Runx2, Osx and Col } \\
X \text { increased at } 2 \mathrm{w} \text {, but decreased at } 4 \mathrm{w}\end{array}$ & $\begin{array}{l}\text { Wang et al } \\
2013^{65}\end{array}$ \\
\hline \multirow[t]{3}{*}{$\begin{array}{l}\text { Trauma } \\
\text { factors }\end{array}$} & Rabbit & ADD & TMJ-OA & $\begin{array}{l}\text { Degenerative changes in cartilage along with the } \\
\text { increased expression of CHOP, GRP78, cleaved } \\
\text { caspase-3, and caspase- } 12\end{array}$ & $\begin{array}{l}\text { Xu et al } \\
2018^{70}\end{array}$ \\
\hline & Rabbit & $\begin{array}{l}\text { Partial perforations of } \\
\text { the discs }\end{array}$ & TMJ-OA & $\begin{array}{l}\text { IL-I stimulates the release of degradative } \\
\text { enzymes and inhibits the synthesis of matrix } \\
\text { proteins, including type II collagen and aggrecan; } \\
\text { synoviocyte proliferation, cartilage and } \\
\text { subchondral cancellous bone lesions }\end{array}$ & $\begin{array}{l}\text { Zhang et al } \\
2011^{71} \\
\text { Liu et al } \\
2011^{72}\end{array}$ \\
\hline & Rabbit & $\begin{array}{l}\text { Extra-articular } \\
\text { surgery causing joint } \\
\text { disc displacement or } \\
\text { deformation }\end{array}$ & TMJ-OA & $\begin{array}{l}\text { Anterior disc displacement or disc deformity, } \\
\text { fibrous adhesions in joint compartment, the } \\
\text { condyles or articular eminences showed } \\
\text { irregularities on the cartilage surface, bad disc } \\
\text { deformity and severe fibrous adhesions, } \\
\text { subchondralbone and calcified cartilage became } \\
\text { irregular }\end{array}$ & $\begin{array}{l}\text { Liu et al } \\
2006^{73}\end{array}$ \\
\hline \multirow[t]{2}{*}{$\begin{array}{l}\text { Mechanical } \\
\text { factors }\end{array}$} & Rat & $\begin{array}{l}\text { Excessive mechanical } \\
\text { stress }\end{array}$ & TMJ-OA & $\begin{array}{l}\text { Cartilage thinning, reduced chondrocyte } \\
\text { numbers, low proliferation, extracellular matrix } \\
\text { degradation, and subchondral bone erosion }\end{array}$ & $\begin{array}{l}\text { Li et al } \\
2013^{77}\end{array}$ \\
\hline & Rabbit & $\begin{array}{l}\text { Prolonged mouth } \\
\text { opening }\end{array}$ & TMJ-OA & $\begin{array}{l}\text { VEGF was expressed in the chondrocytes of the } \\
\text { mature and hypertrophic cell layers of the } \\
\text { intermediate and posterior region of the } \\
\text { condyle, significant increment of osteoclasts in } \\
\text { the mineralized layer subjacent to the } \\
\text { hypertrophic layer }\end{array}$ & $\begin{array}{l}\text { Fujisawa et a } \\
2003^{78} \\
\text { Tanaka et al } \\
2005^{79}\end{array}$ \\
\hline
\end{tabular}

(Continued) 
Table I (Continued).

\begin{tabular}{|l|l|l|l|l|l|}
\hline Types & Species & Methods & Signs/Symptoms & $\begin{array}{l}\text { Pathological Manifestations and } \\
\text { Neurophysiological Mechanisms }\end{array}$ & References \\
\hline Mice & $\begin{array}{l}\text { Prolonged mouth } \\
\text { opening }\end{array}$ & $\begin{array}{l}\text { Persistent orofacial } \\
\text { mechanical allodynia } \\
\text { and TMJ dysfunction }\end{array}$ & $\begin{array}{l}\text { Masseter muscle dystrophy, and increased } \\
\text { proteoglycan deposition and hypertrophic } \\
\text { chondrocytes in the mandibular condyle, } \\
\text { increased F4/80 macrophages in the masseter } \\
\text { muscles and the TMJ posterior synovium, ATF3 } \\
\text { neuronal injury and increased F4/80 } \\
\text { macrophages in the trigeminal ganglia }\end{array}$ & $\begin{array}{l}\text { Wang et al } \\
2018^{80}\end{array}$ \\
\hline $\begin{array}{l}\text { Psychological } \\
\text { factors }\end{array}$ & Rat & CUMS & $\begin{array}{l}\text { Changes of the } \\
\text { behavior, degenerative } \\
\text { changes in the TMJ disc } \\
\text { and condyles }\end{array}$ & $\begin{array}{l}\text { Masticatory muscle function disorders, } \\
\text { abnormal TMJ movement combined with } \\
\text { masticatory muscle function disorders; changes } \\
\text { in the ultrastructural morphology of the TMJ } \\
\text { and degenerative changes }\end{array}$ & $\begin{array}{l}\text { Jun et al } \\
2009^{23}\end{array}$ \\
\hline Rat & $\begin{array}{l}\text { Alternating current } \\
\text { electric box } \\
\text { stimulation }\end{array}$ & $\begin{array}{l}\text { Changes of TMJ and } \\
\text { masseter muscles }\end{array}$ & $\begin{array}{l}\text { Incomplete gelatinlike material on the condyle, } \\
\text { wider waves on the articular disc and exposed } \\
\text { condylar collagen, and cracks were apparent on } \\
\text { the surface of the condyle, increased expression } \\
\text { of IL-I and IL-6 in the condyle cartilage } \\
\text { increased }\end{array}$ & $\begin{array}{l}\text { Wu et al } \\
207\end{array}$ \\
\hline
\end{tabular}

Abbreviations: ADAMTs-5, a disintegrin and metalloproteinase with thrombospondin motifs; ADD, anterior disc displacement; ALP, alkaline phosphatise; ATF3, activating transcription factor 3; BSA, bovine serum albumin; CFA, complete Freund's adjuvant; CGPR, calcitonin gene-related peptide; CGRP-ir, CGRP-immunoreactive; CHOP, C/EBP homologous protein; ColX, type $X$ collagen; CUMS, chronic unpredictable mild stress; ECDO, experimentally created disordered occlusion; GRP78, glucose-regulated protein 78; IL-I, interleukin-I; IL-6, interleukin-6; MIA, mono-iodoacetate; MMP, metalloproteinase; OPN, osteopontin; Osx, osterix; RANKL/OPG, receptor activator of NF- $\kappa B$ ligand/osteoprotegerin; Runx2, runt-related transcription factor 2; TGF $\beta$ I, transforming growth factor $\beta$ I; TGF $\beta$ r2, transforming growth factor $\beta 2$ receptor; TIMP, tissue inhibitors of matrix metalloproteinases; TMJ-OA, temporomandibular joint-osteoarthritis; TNC, trigeminal nucleus caudalis; TNF, tumor necrosis factor; TRAP, tartrate-resistant acid phosphatase; UAC, unilateral anterior crossbite; VEGF, vascular endothelial growth factor.

et $\mathrm{al}^{35}$ found that in the early stage of TMJ-OA, the expression of a disintegrin and metalloproteinase with thrombospondin motifs (ADAMTs-5) and tissue inhibitors of matrix metalloproteinases (TIMP3) significantly increased, indicating that these proteins may be involved in the occurrence of initial stage of condylar cartilage degradation.

It is well known that vascular endothelial growth factor (VEGF) is a potent, pro-angiogenic growth factor that expresses in synoviocytes and chondrocytes during cartilage growth. Both VEGF and its receptors have been detected within the superficial chondrocyte layer in growing articular cartilage. ${ }^{36}$ In the TMJ, VEGF is involved in articular cartilage destruction and TMJ-OA development. It has been shown that high VEGF expression in the condylar cartilage of TMJ-OA model, suggesting an important role of VEGF in the development of TMJ-OA. Intra-articular injection of exogenous VEGF once a week over 4 weeks in the TMJ of mice induced gradual prominent cartilage degeneration, subchondral bone destruction and resorption were confirmed using micro-CT analysis in VEGF-injected mice. VEGF may increase the expression of metalloproteinase-9 (MMP-9) and MMP-13 in chondrocytes and cause chondrocyte apoptosis through VEGF2 receptor, then leading to cartilage degeneration and making this model of TMJ-OA can be used to explore the molecular mechanisms of TMJ-OA. ${ }^{37}$

Two different chemical inductors, papain and sodium mono-iodoacetate (MIA, an inhibitor of glycolysis), were applied by arthrocentesis to induce OA in the TMJ of rabbits. MIA-injection induced various histological changes in the knee joints that intimately resemble OA of humans ${ }^{38}$ and papain affected the components of the extracellular matrix of the joint, imitating the primary changes observed in the OA. ${ }^{39}$ After 15 and 30 days post-induction by MIA, the TMJ presented histological characteristics, and the changes of OA were stable after 60 days, ${ }^{40}$ while the induction by papain determined less significant changes. ${ }^{41}$ Furthermore, OA of TMJ induced by MIA showed a higher degree of severity after induction, which was directly related to its exposure time and the concentration given, suggesting that this animal model can be used in TMJ-OA studies. In addition, female rats were injected with varied doses of MIA into the upper 


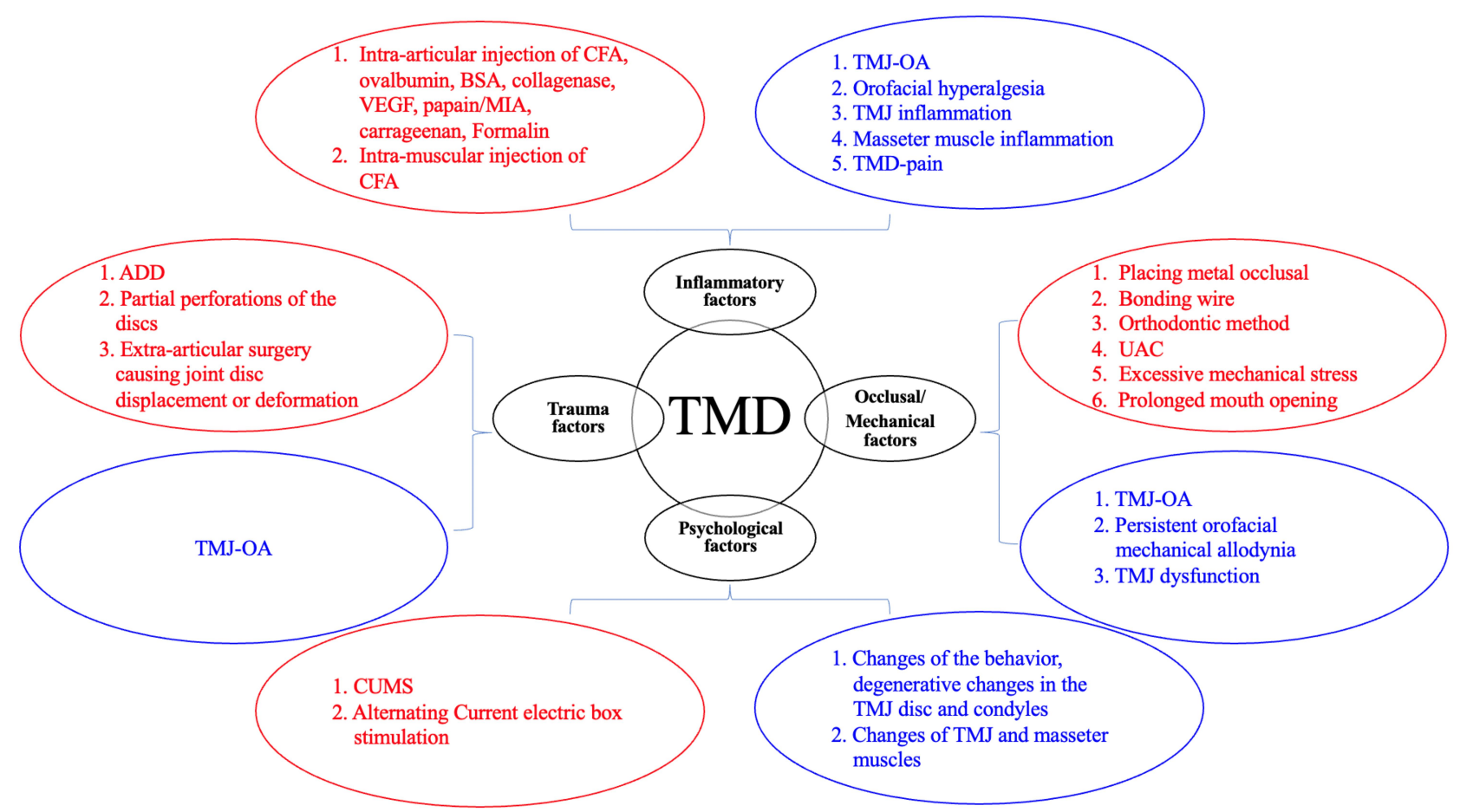

Figure I Schematic diagram of the establishment methods and symptoms for TMD animal models. The red circles represent the establishment methods for different causes of TMD, and the blue circles represent the signs and symptoms produced by TMD models.

Abbreviations: ADD, anterior disc displacement; BSA, bovine serum albumin; CFA, complete Freund's adjuvant; CUMS, chronic unpredictable mild stress; MIA, monoiodoacetate; TMJ-OA, temporomandibular joint-osteoarthritis; UAC, unilateral anterior crossbite; VEGF, vascular endothelial growth factor.

compartment of TMJ and observed for up to 12 weeks. ${ }^{42}$ These results demonstrate a reliable and convenient rat model of TMJ-OA. On the basis of this model, Wang et $\mathrm{al}^{43}$ found that $17 \beta$-estradiol (E2) could aggravate MIA-induced TMJ-OA in ovariectomized (OVX) rats through enhancing chondrocyte apoptosis, which lead to the disruption of cartilage integrity in OA. Simultaneously, they verified that genes of the death receptor family, involving Fas and FasL, were related to chondrocyte apoptosis and up-regulated in this animal model. ${ }^{42,44}$

Intra-articular injection of chemical carrageenan also induced acute TMJ inflammation. ${ }^{45}$ This model was created by administering carrageenan into one joint and an equivalent volume of saline into the contralateral joint of male New Zealand white rabbits, providing a reproducible and reliable approach to explore the time course of inflammatory mediator release and their modulation by anti-inflammatory medications. Rodrigues et $\mathrm{al}^{46}$ further validated that carrageenaninduced TMJ inflammatory hyperalgesia model in rats by showing that administration of indomethacin before the initiation of inflammation diminished the TMJ hyperalgesia. Furthermore, they showed that sympathomimetic amines such as norepinephrine contribute to the development of TMJ hyperalgesia, by acting at $\beta 2$-adrenoceptors located in the TMJ region. Oliveira et $\mathrm{al}^{47}$ found that co-application of the general adenosine triphosphate $\mathrm{P} 2$ receptor antagonist with carrageenan significantly reduced the carrageenan-induced TMJ hyperalgesia, implying $\mathrm{P} 2 \mathrm{X}$ receptors as potential targets for the development of new analgesic drugs to control TMJ pain.

Formalin can produce biphasic nociceptive responses when injected into the rat hind paw and is a noxious stimulus often used in animal behavioral experiments. ${ }^{48}$ Thus, Roveroni et $\mathrm{al}^{49}$ injected different concentrations of formalin into the TMJ region of rats to develop an experimental behavioral model of TMJ pain. It was found that the formalininduced behavioral responses including head flinches and orofacial rubbing increased for concentrations of formalin above $1.5 \%$ for 45 mins. Similar to the examination of carrageenan-induced behavioral responses, in this model, TMJ hyperalgesia is assessed by measuring the behavioral nociceptive responses, such as rubbing the orofacial region and flinching the head. However, the effect of carrageenan-induced TMJ inflammatory hyperalgesia is tested up to $7 \mathrm{~h}$ after application and formalin is acute in that all assessments were made within 45 mins of application, showing certain limitations in conducting experimental research. 
As for intramuscular injection, a previous study confirmed that injection of CFA into the masseter muscle induced mechanical allodynia for 3 weeks, thermal hyperalgesia for 1 week and an increase of CGRP-immunoreactive muscle afferent neurons in the trigeminal ganglion. ${ }^{50}$ Therefore, CFAinduced craniofacial muscle inflammation extends the way to create animal models for masticatory muscle inflammation of TMD. Traub et $\mathrm{al}^{51}$ injected CFA into both the masseter muscles of rats to simulate masticatory muscle inflammatory TMD. Even though the CFA injection is simple and reproducibly to induce TMJ inflammation, most animal models utilizing CFA have focused on small rodent models, thus in the future more studies will be needed in larger animal models to ensure translation of the findings.

In general, most chemical approaches have focused on the inflammatory aspect of TMD and its relationship to pain, and several studies used injection methods to induce degeneration or OA model. The state of inflammation maintains for a short period of time, while the changes of TMJ as a result of OA need to be observed for a longer time. Obviously, chemical approaches seem simple operation, controllable damage and reproducible, but most are used in rodents and only simulate a single factor of inflammation. Therefore, the application of this method in larger animals such as sheep and pigs still needs further study.

\section{Occlusal Factors}

Dental occlusion is necessary for the stability of the craniomandibular system, including teeth, masticatory muscles and TMJs, which are associated with TMD. Although some researchers have put forward an argument through a systematic literature review, indicating that there seems to lack ground to further hypothesis a role for dental occlusion in the pathophysiology of TMD. ${ }^{52}$ It has been confirmed that disturbed occlusion may lead to an imbalance of the masticatory system and become an initiator, a predisposing or perpetuating factor in TMD etiology. ${ }^{53}$ Therefore, nowadays many researchers have established dental occlusion animal models to simulate the occurrence and development of TMD.

An altered occlusion model was established by placing a $1 \mathrm{~mm}$ metal occlusal pad on unilateral molars of New Zealand white rabbits for 6 weeks. The unilateral splint caused uneven condylar fibrocartilage degeneration, which resulted in the activation of the nerves in the synovium or subchondral bone and consequently the pain responses of the rabbits were increased, ${ }^{54}$ but there were no changes in the TMJ disc. ${ }^{55}$ These results suggest a possible explanation that why some patients have TMJ pain, but no TMJ disc problems. However, more studies are needed to investigate the connection between TMJ changes and the development of TMD-pain and longer time points are essential to clarify if disc changes would occur. In a word, this model is advantageous because the joint capsule is not penetrated and it provides various approaches to understanding TMD such as pain and kinematic assessments. On the other hand, these results also suggest that altered loading is the cause rather than the effect in TMD. ${ }^{56,57}$ Simultaneously, this model has limitations. For example, though the rabbit is larger than many other animal models, its mouth is still too small to conduct dental procedures, and the number of soft tissues provided for testing is still limited.

Given that the altered occlusion could lead to OA, a study has developed a malocclusion animal model by bonding a wire to the maxillary molar teeth of 8-week-old mice indefinitely, which was similar to that used by Walker and coworkers. ${ }^{58}$ This new technique used stainless steel wire, which was cut into $5 \mathrm{~mm}$ sections and each section was folded in half such that the final product was a "U" shaped piece approximately $2.5 \mathrm{~mm}$ long, dental mandibular separator and cheek retractor were used in keeping the mouth open and allowing proper placement of the wire on the molars. The development of TMJ-OA was observed as early as two weeks post-misalignment, the cartilage degradation and elevated levels of catabolic biomarker expression were demonstrated after 8 weeks. ${ }^{59}$ This model demonstrated that upregulation of receptor for advanced glycation end products (RAGE) induced OA, and chronic inflammation mediated by RAGE signaling might be one mechanism for TMJ-OA. As the mechanical nature of the malocclusion is similar to the natural development of $\mathrm{OA}$ in humans, this model is ideal to explore the pathogenesis and treatment of TMJ-OA. Additionally, this is an inexpensive, efficient, highly reproducible and non-invasive model of TMJ$\mathrm{OA}$ in mice.

Jiao et $\mathrm{al}^{60}$ designed abnormal occlusion by orthodontic methods, which was called the experimentally created disordered occlusion (ECDO). In this model, the first and third molars of the left maxilla and right mandible were moved mesially and distally, respectively. An elastic rubber band was used to ensure the occlusal contact relationship not be interfered. At the 8th and 12th week after this surgery, an obvious subchondral bone loss followed cartilage degradation in the mandibular condyles and increased death of chondrocytes were observed, ${ }^{61}$ which were sex-related and progressed with time, and OA-like lesions were induced accompanied by changes in the expression of MMP-3, MMP-9, tissue 
inhibitors of matrix metalloproteinases (TIMP-1) and aggrecan, as well as active interaction of stromal cell-derived factor1 (SDF-1)/CXCR4 axis and local up-regulation of MMP9, IL6, and OPG. ${ }^{62,63}$ In addition, an increased number of CD163+ (a member of the scavenger receptor cysteine-rich superfamily) chondrocytes with enhanced phagocytic activity were found within degraded joint cartilage in this model, ${ }^{64}$ providing a new strategy for the treatment of TMJ-OA. However, as the obvious differences in occlusion and TMJ structure between rats and human, this OA-like lesion cannot be completely equivalent to human OA-like lesions.

Another malocclusion animal model has been established by Zhang et al. ${ }^{65}$ They used a unilateral anterior crossbite (UAC) procedure, which induced OA-like changes in the TMJ cartilage of rats by binding to the left and upper mandibular incisors with a metal tube, causing the incisor $135^{\circ}$ lip tilted anti-occlusal guide, which mimicked human conditions of malocclusion. ${ }^{65}$ This procedure induced acute, mild and reversal changes in both the masseter and lateral pterygoid muscles of rats at the early stage, ${ }^{66}$ with the deposition of basic calcium phosphate (BCP)-like minerals in osteoarthritic cartilage, which stimulated matrix degradation by promoting the expression of cartilage-degrading enzymes to facilitate OA progression. ${ }^{67}$ In addition, through this kind of malocclusion model, orofacial hyperalgesia was found from day 1 to day 7 , with a peak on day 3 , accompanied with the central sensitization through the activation of extracellular signal-regulated kinase (ERK) 1/2 mainly in neurons as well as in microglia of the spinal trigeminal subnucleus caudalis ( $\mathrm{Vc}$ ) and the activation of p38 in both neurons and microglia of the Vc. ${ }^{68}$ These results suggest that activated ERK1/2 affects p-p38 expression in neurons and microglia, which has enhanced the UAC-elicited p-p38 expression and contributed to orofacial hyperalgesia. Recently, a study shows that UAC activates the lateral habenula ( $\mathrm{LHb})$ neurons as well as the periodontal proprioceptive pathway to provide excitatory input to the trigeminal afferents (Vme) and produces anxiety in rats, which provides a possible explanation of malocclusion patients experiencing emotional stress and masseter hyperactivity, a common situation in TMD patients. ${ }^{69}$ Despite the created UAC prosthesis seldom occurs clinically, this model provides evidence that abnormal anterior occlusion plays a role in the development of TMJ-OA, and provides an experimental basis for studies on treatments of TMD.

While these studies provide a suitable foundation to induce degeneration of the joint, malocclusion created by mechanical methods may be efficient, highly reproducible, as well as being cheap and presenting little risk for the animals, but their pathological state cannot be equated with human being thoroughly. It is still important to examine how well differences between animals and human critically, and longer time points could be used to help explain this phenomenon.

\section{Trauma and Mechanical Factors}

Destroying the TMJ structure through surgical methods such as removing the articular disc or damaging the cartilage on the joint surface directly can be used as a research method for TMD models. Moreover, some mechanical factors can be risks for the development of TMD, such as prolonged mouth opening.

Anterior disc displacement (ADD) is commonly associated with the beginning of TMD and then it has been regarded as a common surgical model for TMD in animals. $\mathrm{Xu}$ et $\mathrm{al}^{70}$ utilized adult rabbits to surgically induce ADD. Specifically, a $3 \mathrm{~cm}$ incision was made along the right zygomatic arch, and the zygomatic-squamosal suture was exposed in the anesthetized rabbit. Then, the zygomatic process was separated, and a hole was drilled under the anterior process on the superior margin of the zygomatic arch. The anterior part of the disc was then pulled anteriorly and anchored to the hole using elastic rubber. Following surgical ADD, enhanced chondrocyte apoptosis occurred in rabbit cartilage, leading to a decrease in cell density. In addition, they found for the first time that endoplasmic reticulum stress (ERS) pathway might be involved in the development of $\mathrm{ADD}$, providing new insight that ER stress pathway may become potential therapeutic target for TMD.

Partial disc perforation was applied bilaterally to induce TMJ-OA in rabbits, which resected one-third of the disc in the anterior and lateral regions of the joint, then induced OA lesions to joint structures. ${ }^{71,72}$ Indirect trauma to the TMJ can also cause TMD and mandibular developmental disorders, inducing various TMJ diseases. Liu et $\mathrm{al}^{73}$ used extra-articular surgery to unilaterally pull the rabbit's lower jaw backward, causing joint disc displacement or deformation, synovial hyperplasia occurred early in the postoperative period, and adhesion in joints, a severe deformation of the joint disc at 6 weeks after the operation, appearing typical OA pathological manifestations. Even though this model does not damage the joint capsule and joint disc attachment, and to some extent maintains the integrity of the joint structure, it is still quite different from the occurrence and development of human TMD. Regarding surgical approaches, they supply insight into the process of joint degeneration by both normal pathogenesis, like ADD and partial disc perforation. Most surgical approaches are used in large animal models which have not 
been as widely cited as the smaller animal models. Meanwhile, the destruction of the joint structure during surgery may interfere with the natural progression of TMD.

There is a strong relationship between mechanical stress and the development of chronic TMD. ${ }^{74}$ Excessive mechanical stress has been assumed as one of the major involved factors contributing to the TMJ-OA, ${ }^{75}$ and compressive mechanical stress-induced cartilage thinning presents as a primary stage in the progression of TMJ-OA. ${ }^{76}$ $\mathrm{Li}$ et $\mathrm{al}^{77}$ used a rat model to load compressive mechanical stress on mandibular cartilage, and found obvious cartilage thinning, reduced chondrocyte numbers, low proliferation, extracellular matrix degradation, and subchondral bone erosion. Specifically, a rubber band was tied between the $\mathrm{jig}$ and the anchorage hooks to load $40 \mathrm{~g}$ of force on each side, and X-ray images were used to show the direction of mechanical stress loading. Through this research, prolonged mouth opening acting as a kind of mechanical stress is used to develop OA model, providing a new insight into the role of ERS in regulating OA and promoting the identification of novel therapeutic objectives for treating TMJ diseases. Fujisawa et $\mathrm{al}^{78}$ reported a genuine mechanical-stress-induced OA model of the rabbit TMJ by forced mouth opening with a repetitive, steady, mouth opening of $3 \mathrm{~h}$ /day for 5 days. Considering this finding, Tanaka et $\mathrm{al}^{79}$ imposed mechanical stress that forced mouth opening of $30 \mathrm{~mm}$ for $1 \mathrm{~h}$ /day in the rabbit TMJ. After 20 days of forced mouth opening, obvious OA-like lesions were recognized, which were similar to those observed in TMJ-OA patients, suggesting that VEGF plays an important autocrine or paracrine role in the initiation and progression of OA in the TMJ simultaneously. Recently, Wang et $\mathrm{al}^{80}$ reported a new mouse model of TMD in which a bite block was placed between the upper and lower incisors so that the mouth was kept maximally open for $1.5 \mathrm{~h}$ /day for 5 days, suggesting inflammation associated with macrophage/microglia in the tissue and trigeminal system plays a part in the development of TMD pain, which is the first time that the clinical validity of a mouth opening animal model is thoroughly researched and convinced. The mice developed persistent orofacial mechanical allodynia and TMJ dysfunction accompanying sustained mouth opening. Generally, these models follow the natural course of TMD onset of human, and avoid extra tissue damage of joint structures. However, there are several latent limitations, such as a clinically relevant vertical height of mouth opening, occurrence of adverse trauma or joint dislocation, valuation of orofacial pain in animals in a reliable pain assessment system.

\section{Psychological Factors}

It has been shown that psychological stress plays a vital role in the occurrence and development of TMD, which may occur when an organism perceives an inability to cope with a "challenge" or fails to respond appropriately to emotional or physical threats. ${ }^{81,82}$ Gaballah et al conducted a population-based cross-sectional study of 2101 individuals between the ages of 19 and 60 . Through detailed analysis of the questionnaire survey results, they found the importance of psychological factors in the pathogenesis of TMD. ${ }^{83}$ Psychological stress state, such as anxiety and depression is related to TMJ diseases or dysfunction and may negatively impact the quality of life. Besides, psychological stress can cause spasms and disharmony in the chewing muscle groups. Clinical studies have shown that higher prevalence rates of psychiatric disorders among patients with TMD when compared to healthy people. ${ }^{84}$ Since psychological factors are risk factors for TMD, ${ }^{85,86}$ several experimental animal models of TMD were established from psychological factors.

Liang et $\mathrm{al}^{23}$ performed chronic unpredictable mild stress (CUMS) stimulation on single-cage orphan rats for 6 weeks, including day and night inversion, acupuncture, tail clamping, forced swim, then they found that changes in the behaviors and degeneration in the TMJ disc and condyles, which were consistent with the pathological changes of TMD. Rats under strong emotional stress can cause masticatory muscle function disorders, and abnormal TMJ movement combined with masticatory muscle function disorders are main factors that cause changes in the weight-bearing and uneven stress distribution of the TMJ. Long-term exposure to such a state of adverse stress caused changes in the ultrastructural morphology of the TMJ in rats and degenerative changes, which were consistent with the pathological signs of TMD. Wu et al ${ }^{87}$ established an animal model of psychological stress in rats through alternating current $(\mathrm{AC})$ electric box stimulation, and they found that the TMJ and masseter muscles of rats underwent qualitative changes. Psychological stress may affect the hypothalamus through neural pathways, resulting in the release of corticotropin-releasing hormone, which in turn promotes the secretion of adrenocorticotropic hormone (ACTH) from the pituitary and finally ACTH acts in the adrenal cortex to facilitate the synthesis and release of glucocorticoids, meanwhile, the serum concentration of cortisol and ACTH, the TMJ ultrastructure, and the expression levels of the inflammatory cytokines IL-1 and IL-6 also occur a series of changes. 
Similarly, communication box was used to establish the rat model of psychological stress and found that psychological stress reduced the thickness of the central and posterior regions of the condylar cartilage in rats, and local lesions in the bones below the condylar cartilage were found by micro-CT scans. ${ }^{88}$

Overall, psychological stress approaches reflect the role of psychological factors in the development of TMD patients. Therefore, psychological interventions, such as stress management training, biofeedback and habit reversal, are effective in reducing pain symptoms in patients with TMD. Given that it is difficult to select people as experimental objects to promote research in this area; thus, the establishment of TMD experimental animal models under psychological stress would be of great significance for further research on the pathogenesis of TMD, especially the direction of the psychological axis of TMD biaxial diagnosis, simulating clinical treatment and exploring better treatment avenues for patients.

\section{Animal Models for TMD Comorbid with Other Diseases}

Comorbidity refers to the incidence of two different diseases in the same individual. ${ }^{75}$ Many patients with TMD have pain symptoms in other parts of the body that are not related to the primary disease, leading to comorbidity, and yet the mechanism is still unclear. The most frequent comorbid conditions of TMD involve IBS, FMS, rheumatoid arthritis, chronic headache, depression, and sleep disturbances. ${ }^{89}$ Many patients with TMD report additional pain, resulting in comorbid or overlapping pain syndromes. ${ }^{90,91}$ Several cross-sectional studies have shown that there is an association between TMD and IBS. Sanders et $\mathrm{al}^{92}$ found that the incidence of TMD in people with IBS was three times higher than in people without IBS. In addition, $10 \%$ to $18.4 \%$ of FMS patients have TMD and $71 \%$ to $94 \%$ of TMD patients suffer from FMS. ${ }^{93}$

Traub et $\mathrm{al}^{51}$ established a model of comorbidities of TMD and IBS for the first time, which induced continuous visceral hypersensitivity in rats under the combined effects of estrogen, chronic maxillofacial pain caused by masseter inflammation and stress stimulation. ${ }^{94}$ This model can be used to explore the pathogenesis of the comorbidity of TMD and IBS under stress, providing a stage to investigate underlying mechanisms of these overlapping pain syndromes. Based on this model, our group has found that craniofacial muscle inflammation followed by 3-day forced swim stress induced ERK1/2 activation in lumbosacral spinal segments (L6-S2) in E2 replacement rats, and intrathecal injection of mitogen-activated protein kinase (MAPK) kinase (MEK) inhibitor PD98059 blocked the visceral hypersensitivity induced by masseter muscle inflammation combined with forced swim stress. ${ }^{94}$ These results provide a new therapeutic avenue for alleviating overlapping pain conditions. Recently, $\mathrm{Ji}$ et $\mathrm{al}^{95}$ confirmed that estradiol is pronociceptive and testosterone is antinociceptive in a model of stress-induced visceral hypersensitivity (SIVH) in rats by recording the visceromotor response to colorectal distention following a 3-day forced swim stress. Furthermore, the same stressor that induces transient visceral hypersensitivity (3-4 weeks) evokes long-lasting ( $>13$ weeks) visceral hypersensitivity in the presence of a preexisting orofacial pain by exploiting a model of comorbid pain hypersensitivity $(\mathrm{CPH}) .{ }^{96}$ This animal model will further advance the study of pain associated with TMD and IBS.

The signs and symptoms of FMS are frequently diagnosed as part of TMD, which could be an etiologic or aggravating condition for TMD. FMS and TMD have some common clinical characteristics, such as chronic evolution, the incompletely acknowledged pathophysiology, the severe physical and psychological effects, and the common leading factors. ${ }^{97,98}$ It has been evidenced that TMD is more prevalent in patients with FMS compared with contrasts in the range of $33 \%$ to $97 \%$. ${ }^{99}$ We have successfully established a rat model of masseter muscle inflammation combined with various stress stimulations that cause somatic pain sensitization. ${ }^{25}$ Based on this model, the behavioral indicators such as the thermal paw withdrawal latency and mechanical paw withdrawal threshold were used to evaluate the thresholds of somatic pain and provide an experimental basis for studying the comorbidity mechanism of TMD and FMS. Orofacial inflammation induced by injection of CFA into bilateral masseter muscles simulating the symptoms of TMD combined with different modes of stress stimulation causes somatic pain sensitization, which is the first TMD and FMS comorbid animal model, ${ }^{26}$ providing an ideal animal model for further exploration of comorbidity.

It has been shown that there is comorbidity between TMD and primary headache as TMD symptomatology is more common in patients with primary headaches such as migraine, and the presence of either disorder notably increases the prevalence and exacerbates the other disorder. ${ }^{100,101}$ Romero-Reyes et al102 demonstrated that CGRP is a significant neurotransmitter involved in driving peripheral and central sensitization in the TMD model induced by an intramuscular injection of CFA, without the involvement of inflammatory mechanisms at an acute stage. CGRP antagonist is efficacious at inhibiting spontaneous nociceptive behaviors in the orofacial region and 
neuronal activation in the trigeminal nucleus caudalis (TNC), suggesting that CGRP receptor antagonists may have therapeutic efficacy in the treatment of TMD and comorbidity. ${ }^{27}$

\section{Conclusions}

TMD is a common disease of the oral and maxillofacial region. Due to its occult occurrence and the special anatomy of the TMJ, the clinical studies are difficult to explore. In spite of the variety of TMD models established and the essential neurophysiological mechanisms revealed through them, each model has its own advantages and disadvantages, and most of the current models are single-factor models, which cannot fully reflect the etiology and course of the disease. The valid TMD animal models for the mechanisms and therapeutic studies are still limited. Therefore, it is of great significance to select appropriate experimental animals to mimic TMD both causally and symptomatically and thus exploring better therapeutic approaches for patients. Additionally, it is necessary to comprehensively evaluate various models and create multi-factor models, providing more suitable animal models for in-depth investigation of the neurobiological and molecular mechanisms of TMD. Furthermore, clinical trials are essential because animal studies cannot fully simulate the physiological evolution of humans.

\section{Acknowledgments}

This work was supported by the National Natural Science Foundation of China $(81971049,81671097)$ and the Social Development Program of Shaanxi Province, China (2020SF-018).

\section{Disclosure}

The authors reported no conflicts of interest for this work.

\section{References}

1. Bueno CH, Pereira DD, Pattussi MP, Grossi PK, Grossi ML. Gender differences in temporomandibular disorders in adult populational studies: a systematic review and meta-analysis. J Oral Rehabil. 2018;45 (9):720-729. doi:10.1111/joor.12661

2. Jacobson A. Prevalence of temporomandibular disorder subtypes, psychological distress, and psychosocial dysfunction in Asian patients. Am J Orthod Dentofacial Orthop. 2003;123(5):586-587.

3. Lai YC, Yap AU, Turp JC. Prevalence of temporomandibular disorders in patients seeking orthodontic treatment: a systematic review. J Oral Rehabil. 2020;47(2):270-280. doi:10.1111/joor.12899

4. Schiffman E, Ohrbach R, Truelove E, et al.; International Rdc/Tmd Consortium Network, I. A. F. D. R.; Orofacial Pain Special Interest Group, I. A. F. T. S. O. P. Diagnostic criteria for temporomandibular disorders (DC/TMD) for clinical and research applications: recommendations of the international RDC/TMD consortium network and orofacial pain special interest groupdagger. J Oral Facial Pain Headache. 2014;28(1):6-27. doi:10.11607/jop.1151
5. Takashima M, Arai Y, Kawamura A, Hayashi T, Takagi R. Quantitative evaluation of masseter muscle stiffness in patients with temporomandibular disorders using shear wave elastography. J Prosthodont Res. 2017;61(4):432-438. doi:10.1016/j.jpor.2017.01.003

6. Durham J, Steele JG, Wassell RW, Exley C. Living with uncertainty: temporomandibular disorders. J Dent Res. 2010;89 (8):827-830. doi:10.1177/0022034510368648

7. Paulino MR, Moreira VG, Lemos GA, Silva P, Bonan PRF, Batista AUD. Prevalence of signs and symptoms of temporomandibular disorders in college preparatory students: associations with emotional factors, parafunctional habits, and impact on quality of life. Cien Saude Colet. 2018;23(1):173-186. doi:10.1590/1413-81232018231.18952015

8. Liu F, Steinkeler A. Epidemiology, diagnosis, and treatment of temporomandibular disorders. Dent Clin North Am. 2013;57 (3):465-479. doi:10.1016/j.cden.2013.04.006

9. Manfredini D. Etiopathogenesis of disk displacement of the temporomandibular joint: a review of the mechanisms. Indian J Dent Res. 2009;20(2):212-221. doi:10.4103/0970-9290.51365

10. Chisnoiu AM, Picos AM, Popa S, et al. Factors involved in the etiology of temporomandibular disorders - a literature review. Clujul Med. 2015;88(4):473-478. doi:10.15386/cjmed-485

11. Maixner W, Diatchenko L, Dubner R, et al. Orofacial pain prospective evaluation and risk assessment study-the OPPERA study. J Pain. 2011;12(11 Suppl):T4-11e1-2. doi:10.1016/j. jpain.2011.08.002

12. Fiamengui LMSP, Furquim BD, Canales GD, et al. Role of inflammatory and pain genes polymorphisms in temporomandibular disorder and pressure pain sensitivity. Arch Oral Biol. $2020 ; 118$.

13. Ebadian B, Abbasi M, Nazarifar AM. Frequency distribution of temporomandibular disorders according to occlusal factors: a Cross-Sectional Study. Dent Res J (Isfahan). 2020;17 (3):186-192. doi:10.4103/1735-3327.284731

14. Holyoak DT, Chlebek C, Kim MJ, Wright TM, Otero M, van der Meulen MCH. Low-level cyclic tibial compression attenuates early osteoarthritis progression after joint injury in mice. Osteoarthritis Cartilage. 2019;27(10):1526-1536. doi:10.1016/j. joca.2019.06.005

15. Sojka A, Stelcer B, Roy M, Mojs E, Prylinski M. Is there a relationship between psychological factors and TMD? Brain Behav. 2019;9(9). doi:10.1002/brb3.1360

16. Ohrbach R, Dworkin SF. The evolution of TMD diagnosis: past, present, future. J Dent Res. 2016;95(10):1093-1101. doi:10.1177/ 0022034516653922

17. Gauer RL, Semidey MJ. Diagnosis and treatment of temporomandibular disorders. Am Fam Physician. 2015;91(6):378-386.

18. Wurm MC, Behrends TK, Wust W, et al. Correlation between pain and MRI findings in TMD patients. $J$ Craniomaxillofac Surg. 2018;46(8):1167-1171. doi:10.1016/j.jcms.2017.12.029

19. Yin Y, He S, Xu J, et al. The neuro-pathophysiology of temporomandibular disorders-related pain: a systematic review of structural and functional MRI studies. J Headache Pain. 2020;21 (1):78. doi:10.1186/s10194-020-01131-4

20. Costa YM, Conti PC, de Faria FA, Bonjardim LR. Temporomandibular disorders and painful comorbidities: clinical association and underlying mechanisms. Oral Surg Oral Med Oral Pathol Oral Radiol. 2017;123(3):288-297. doi:10.1016/j. oooo.2016.12.005

21. Moayedi M, Hodaie M. Trigeminal nerve and white matter brain abnormalities in chronic orofacial pain disorders. Pain Rep. 2019;4(4):e755. doi:10.1097/PR9.0000000000000755

22. Moayedi M, Weissman-Fogel I, Crawley AP, et al. Contribution of chronic pain and neuroticism to abnormal forebrain gray matter in patients with temporomandibular disorder. Neuroimage. 2011;55(1):277-286. doi:10.1016/j.neuroimage.2010.12.013 
23. LiangJ, Chen Y, Min HU, Zhang LH, Niu Y. TMD animal model in rats induced by chronic unpredictable emotional stress. Lab Anim Sci. 2009;26(1):11-14.

24. Harper DE, Schrepf A, Clauw DJ. Pain mechanisms and centralized pain in temporomandibular disorders. J Dent Res. 2016;95 (10):1102-1108. doi:10.1177/0022034516657070

25. Li JH, Yang JL, Wei SQ, et al. Contribution of central sensitization to stress-induced spreading hyperalgesia in rats with orofacial inflammation. Mol Brain. 2020;13(1):106. doi:10.1186/ s13041-020-00645-X

26. Xue Y, Wei SQ, Wang PX, et al. Down-regulation of spinal 5-HT2A and 5-HT2C receptors contributes to somatic hyperalgesia induced by orofacial inflammation combined with stress. Neuroscience. 2020;440:196-209. doi:10.1016/j.neuroscience.2020.05.044

27. Romero-Reyes M, Pardi V, Akerman S. A potent and selective calcitonin gene-related peptide (CGRP) receptor antagonist, MK-8825, inhibits responses to nociceptive trigeminal activation: role of CGRP in orofacial pain. Exp Neurol. 2015;271:95-103. doi:10.1016/j.expneurol.2015.05.005

28. Sjoberg EA. Logical fallacies in animal model research. Behav Brain Funct. 2017;13(1):3. doi:10.1186/s12993-017-0121-8

29. Wang XD, Kou XX, Mao JJ, Gan YH, Zhou YH. Sustained inflammation induces degeneration of the temporomandibular joint. J Dent Res. 2012;91(5):499-505. doi:10.1177/0022034512441946

30. Xu L, Guo H, Li C, Xu J, Fang W, Long X. A time-dependent degeneration manner of condyle in rat CFA-induced inflamed TMJ. Am J Transl Res. 2016;8(2):556-567.

31. Rafayelyan S, Meyer P, Radlanski RJ, Minden K, JostBrinkmann PG, Prager TM. Effect of methotrexate upon antigen-induced arthritis of the rabbit temporomandibular joint. J Oral Pathol Med. 2015;44(8):614-621. doi:10.1111/jop.12265

32. Kapila S, Lee C, Tavakkoli Jou MR, Miller AJ, Richards DW. Development and histologic characterizations of an animal model of antigen-induced arthritis of the juvenile rabbit temporomandibular joint. J Dent Res. 1995;74(12):1870-1879. doi:10.1177/ 00220345950740121001

33. Naujokat H, Sengebusch A, Mller B, Wieker H, Ail Y, Wiltfang J. Antigen-induced arthritis of the temporomandibular joint via repeated injections of bovine serum albumin in domestic pigs. J Craniomaxillofac Surg. 2019;47(6):932-939. doi:10.1016/j. jcms.2019.03.001

34. Imada M, Tanimoto K, Ohno S, Sasaki A, Sugiyama H, Tanne K. Changes in urinary bone resorption markers (pyridinoline, deoxypyridinoline) resulting from experimentally-induced osteoarthritis in the temporomandibular joint of rats. Cranio. 2003;21 (1):38-45. doi:10.1080/08869634.2003.11746230

35. Li W, Wu M, Jiang S, Ding W, Luo Q, Shi J. Expression of ADAMTs-5 and TIMP-3 in the condylar cartilage of rats induced by experimentally created osteoarthritis. Arch Oral Biol. 2014;59 (5):524-529. doi:10.1016/j.archoralbio.2014.02.016

36. Lingaraj K, Poh CK, Wang W. Vascular endothelial growth factor (VEGF) is expressed during articular cartilage growth and re-expressed in osteoarthritis. Ann Acad Med Singap. 2010;39(5):399-403.

37. Shen P, Jiao ZX, Zheng JS, et al. Injecting vascular endothelial growth factor into the temporomandibular joint induces osteoarthritis in mice. Sci Rep. 2015;5(1). doi:10.1038/srep16244

38. Guzman RE, Evans MG, Bove S, Morenko B, Kilgore K. Monoiodoacetate-induced histologic changes in subchondral bone and articular cartilage of rat femorotibial joints: an animal model of osteoarthritis. Toxicol Pathol. 2003;31(6):619-624. doi:10.1080/ 01926230390241800

39. Cledes G, Felizardo R, Foucart JM, Carpentier P. Validation of a chemical osteoarthritis model in rabbit temporomandibular joint: a compliment to biomechanical models. Int $J$ Oral Maxillofac Surg. 2006;35(11):1026-1033. doi:10.1016/j. ijom.2006.05.003
40. Artuzi FE, Langie R, Abreu M. Rabbit model for osteoarthrosis of the temporomandibular joint as a basis for assessment of outcomes after intervention. Br J Oral Maxillofac Surg. 2016;54(5): e33-e37. doi:10.1016/j.bjoms.2016.01.022

41. Molinet M, Alves N, Vasconcelos A, Deana NF. Comparative study of osteoarthritis (OA) induced by monoiodoacetate (MIA) and papain in rabbit temporomandibular joints: macroscopic and microscopic analysis. Folia Morphol. 2020;79(3):516-527. doi:10.5603/FM.a2019.0104

42. Wang XD, Kou XX, He DQ, et al. Progression of cartilage degradation, bone resorption and pain in rat temporomandibular joint osteoarthritis induced by injection of iodoacetate. PLoS One. 2012;7(9):e45036. doi:10.1371/journal.pone.0045036

43. Wang XD, Kou XX, Meng Z, et al. Estrogen aggravates iodoacetate-induced temporomandibular joint osteoarthritis. $J$ Dent Res. 2013;92(10):918-924. doi:10.1177/0022034513501323

44. Hussain S, Lawrence MG, Taylor RA, et al. Estrogen receptor beta activation impairs prostatic regeneration by inducing apoptosis in murine and human stem/progenitor enriched cell populations. PLoS One. 2012;7(7):e40732. doi:10.1371/journal. pone. 0040732

45. Swift JQ, Roszkowski MT, Alton T, Hargreaves KM. Effect of intra-articular versus systemic anti-inflammatory drugs in a rabbit model of temporomandibular joint inflammation. $J$ Oral Maxillofac Surg. 1998;56(11):1288-1295. discussion 1295-6. doi:10.1016/S0278-2391(98)90611-5

46. Rodrigues LL, Oliveira MC, Pelegrini-da-silva A, de Arruda Veiga MC, Parada CA, Tambeli CH. Peripheral sympathetic component of the temporomandibular joint inflammatory pain in rats. $J$ Pain. 2006;7(12):929-936. doi:10.1016/j.jpain.2006.05.006

47. Oliveira MC, Parada CA, Veiga MC, Rodrigues LR, Barros SP, Tambeli CH. Evidence for the involvement of endogenous ATP and P2X receptors in TMJ pain. Eur J Pain. 2005;9(1):87-93. doi:10.1016/j.ejpain.2004.04.006

48. Taylor BK, Peterson MA, Basbaum AI. Persistent cardiovascular and behavioral nociceptive responses to subcutaneous formalin require peripheral nerve input. $J$ Neurosci. 1995;15 (11):7575-7584. doi:10.1523/JNEUROSCI.15-11-07575.1995

49. Roveroni RC, Parada CA, Cecilia M, Veiga FA, Tambeli CH. Development of a behavioral model of TMJ pain in rats: the TMJ formalin test. Pain. 2001;94(2):185-191. doi:10.1016/S03043959(01)00357-8

50. Ambalavanar R, Yallampalli C, Yallampalli U, Dessem D. Injection of adjuvant but not acidic saline into craniofacial muscle evokes nociceptive behaviors and neuropeptide expression. Neuroscience. 2007;149(3):650-659.

51. Traub RJ, Cao DY, Karpowicz J, et al. A clinically relevant animal model of temporomandibular disorder and irritable bowel syndrome comorbidity. J Pain. 2014;15(9):956-966. doi:10.1016/j.jpain.2014.06.008

52. Manfredini D, Lombardo L, Siciliani G. Temporomandibular disorders and dental occlusion. A systematic review of association studies: end of an era? J Oral Rehabil. 2017;44(11):908-923. doi:10.1111/joor.12531

53. Turp JC, Schindler H. The dental occlusion as a suspected cause for TMDs: epidemiological and etiological considerations. J Oral Rehabil. 2012;39(7):502-512. doi:10.1111/j.13652842.2012.02304.x

54. Henderson SE, Tudares MA, Gold MS, Almarza AJ. Analysis of pain in the rabbit temporomandibular joint after unilateral splint placement. J Oral Facial Pain Headache. 2015;29(2):193-202. doi:10.11607/ofph.1371

55. Henderson SE, Lowe JR, Tudares MA, Gold MS, Almarza AJ. Temporomandibular joint fibrocartilage degeneration from unilateral dental splints. Arch Oral Biol. 2015;60(1):1-11. doi:10.1016/ j.archoralbio.2014.08.022 
56. Ingawale $\mathrm{S}$, Goswami $\mathrm{T}$. Temporomandibular joint: disorders, treatments, and biomechanics. Ann Biomed Eng. 2009;37 (5):976-996. doi:10.1007/s10439-009-9659-4

57. Tanaka E, Detamore MS, Mercuri LG. Degenerative disorders of the temporomandibular joint: etiology, diagnosis, and treatment. J Dent Res. 2008;87(4):296-307. doi:10.1177/ 154405910808700406

58. Walker CG, Ito $\mathrm{Y}$, Dangaria $\mathrm{S}$, Luan $\mathrm{X}$, Diekwisch $\mathrm{TGH}$. RANKL, osteopontin, and osteoclast homeostasis in a hyperocclusion mouse model. Eur J Oral Sci. 2008;116 (4):312-318. doi:10.1111/j.1600-0722.2008.00545.x

59. Matias EMC, Mecham DK, Black CS, et al. Malocclusion model of temporomandibular joint osteoarthritis in mice with and without receptor for advanced glycation end products. Arch Oral Biol. 2016;69:47-62. doi:10.1016/j.archoralbio.2016.05.007

60. Jiao K, Wang MQ, Niu LN, et al. Death and proliferation of chondrocytes in the degraded mandibular condylar cartilage of rats induced by experimentally created disordered occlusion. Apoptosis. 2009;14(1):22-30. doi:10.1007/s10495-008-0279-5

61. Jiao K, Niu LN, Wang MQ, et al. Subchondral bone loss following orthodontically induced cartilage degradation in the mandibular condyles of rats. Bone. 2011;48(2):362-371. doi:10.1016/j. bone.2010.09.010

62. Wang GW, Wang MQ, Wang XJ, Yu SB, Liu XD, Jiao K. Changes in the expression of MMP-3, MMP-9, TIMP-1 and aggrecan in the condylar cartilage of rats induced by experimentally created disordered occlusion. Arch Oral Biol. 2010;55 (11):887-895. doi:10.1016/j.archoralbio.2010.07.013

63. Kuang B, Dai J, Wang QY, et al. Combined degenerative and regenerative remodeling responses of the mandibular condyle to experimentally induced disordered occlusion. Am J Orthod Dentofacial Orthop. 2013;143(1):69-76. doi:10.1016/j. ajodo.2012.08.024

64. Jiao K, Zhang J, Zhang M, et al. The identification of CD163 expressing phagocytic chondrocytes in joint cartilage and its novel scavenger role in cartilage degradation. PLoS One. 2013;8 (1):e53312. doi:10.1371/journal.pone.0053312

65. Zhang X, Dai J, Lu L, et al. Experimentally created unilateral anterior crossbite induces a degenerative ossification phenotype in mandibular condyle of growing Sprague-Dawley rats. J Oral Rehabil. 2013;40(7):500-508. doi:10.1111/joor.12072

66. Zhang HY, Yang HX, Liu Q, et al. Injury responses of Sprague-Dawley rat jaw muscles to an experimental unilateral anterior crossbite prosthesis. Arch Oral Biol. 2020;109. doi:10.1016/j.archoralbio.2019.104588

67. Zhang M, Wang $\mathrm{H}$, Zhang J, et al. Unilateral anterior crossbite induces aberrant mineral deposition in degenerative temporomandibular cartilage in rats. Osteoarthritis Cartilage. 2016;24 (5):921-931. doi:10.1016/j.joca.2015.12.009

68. Jing L, Liu XD, Yang HX, et al. ERK potentiates p38 in central sensitization induced by traumatic occlusion. Neuroscience. 2017;340:445-454. doi:10.1016/j.neuroscience.2016.11.012

69. Liu X, Zhou KX, Yin NN, et al. Malocclusion generates anxiety-like behavior through a putative lateral habenula-mesencephalic trigeminal nucleus pathway. Front $\mathrm{Mol}$ Neurosci. 2019;12. doi:10.3389/fnmol.2019.00174

70. Xu T, Gu Z, Wu H, Yao H, Wang G. Expression of endoplasmic reticulum stress protein in rabbit condyle cartilage following anterior disc displacement. J Oral Pathol Med. 2018;47 (6):606-612. doi:10.1111/jop.12715

71. Zhang B, Hu J, Man C, Zhu S. Effect of intra-articular administration of interleukin 1 receptor antagonist on cartilage repair in temporomandibular joint. J Craniofac Surg. 2011;22(2):711-714. doi:10.1097/SCS.0b013e31820873c6
72. Liu XW, Hu J, Man C, Zhang B, Ma YQ, Zhu SS. Insulin-like growth factor-1 suspended in hyaluronan improves cartilage and subchondral cancellous bone repair in osteoarthritis of temporomandibular joint. Int J Oral Maxillofac Surg. 2011;40 (2):184-190. doi:10.1016/j.ijom.2010.10.003

73. Liu LK, Hong YJ, Tao DT, Li XQ, Yi XZ. [Evaluation of a model of temporomandibular disorders established by transzygomatic arch traction of the mandibular ramus in rabbits]. Zhong Hua Kou Qiang Yi Xue Za Zhi. 2006;41(12):755-756. Chinese.

74. Ohrbach R, Fillingim RB, Mulkey F, et al. Clinical findings and pain symptoms as potential risk factors for chronic TMD: descriptive data and empirically identified domains from the OPPERA case-control study. J Pain. 2011;12(11):T27-T45. doi:10.1016/j.jpain.2011. 09.001

75. Wu Y, Kadota-Watanabe C, Ogawa T, Moriyama K. Combination of estrogen deficiency and excessive mechanical stress aggravates temporomandibular joint osteoarthritis in vivo. Arch Oral Biol. 2019;102:39-46. doi:10.1016/j.archoralbio.2019.03.012

76. Wadhwa S, Kapila S. TMJ disorders: future innovations in diagnostics and therapeutics. J Dent Educ. 2008;72(8):930-947. doi:10.1002/j.0022-0337.2008.72.8.tb04569.x

77. Li H, Zhang XY, Wu TJ, et al. Endoplasmic reticulum stress regulates rat mandibular cartilage thinning under compressive mechanical stress. J Biol Chem. 2013;288(25):18172-18183. doi:10.1074/jbc.M112.407296

78. Fujisawa T, Kuboki T, Kasai T, et al. A repetitive, steady mouth opening induced an osteoarthritis-like lesion in the rabbit temporomandibular joint. J Dent Res. 2003;82(9):731-735. doi:10.1177/ 154405910308200914

79. Tanaka E, Aoyama J, Miyauchi M, et al. Vascular endothelial growth factor plays an important autocrine/paracrine role in the progression of osteoarthritis. Histochem Cell Biol. 2005;123 (3):275-281. doi:10.1007/s00418-005-0773-6

80. Wang GYF, Shi XQ, Wu WJ, Gueorguieva M, Yang M, Zhang J. Sustained and repeated mouth opening leads to development of painful temporomandibular disorders involving macrophage/ microglia activation in mice. Pain. 2018;159(7):1277-1288. doi:10.1097/j.pain.0000000000001206

81. Jedel E, Carlsson J, Stener-Victorin E. Health-related quality of life in child patients with temporomandibular disorder pain. Eur J Pain. 2007;11(5):557-563. doi:10.1016/j.ejpain.2006.07.007

82. Kindler S, Schwahn C, Bernhardt $\mathrm{O}$, et al. Association between symptoms of posttraumatic stress disorder and signs of temporomandibular disorders in the general population. J Oral Facial Pain Headache. 2019;33(1):67-76. doi:10.1160 7/ofph.1905

83. Gaballah K, Alkubaisy A, Baker AA, Bawzeer A, Awad R. Revisiting the risk factors for multiple symptoms of temporomandibular disorders: a structured cross-sectional study. Open Dent J. 2020;14(1):503-510. doi:10.2174/1874210602014010503

84. Gatchel RJ, Garofalo JP, Ellis E, Holt C. Major psychological disorders in acute and chronic TMD: an initial examination. $J$ Am Dent Assoc. 1996;127(9):1365-70, 1372, 1374. doi:10.14219/ jada.archive. 1996.0450

85. Bertoli FMD, Bruzamolin CD, Kranz GOD, Losso EM, Brancher JA, de Souza JF. Anxiety and malocclusion are associated with temporomandibular disorders in adolescents diagnosed by RDC/TMD. A cross-sectional study. J Oral Rehabil. 2018;45(10):747-755. doi:10.1111/joor.12684

86. Diracoglu D, Yildirim NK, Saral I, et al. Temporomandibular dysfunction and risk factors for anxiety and depression. J Musculoskelet Res. 2016;29(3):487-491. doi:10.3233/BMR150644 
87. Wu G, Chen L, Zhu G, et al. Psychological stress induces alterations in temporomandibular joint ultrastructure in a rat model of temporomandibular disorder. Oral Surg Oral Med Oral Pathol Oral Radiol Endod. 2011;112(6):e106-12. doi:10.1016/j. tripleo.2011.06.005

88. Li Q, Zhang M, Chen YJ, Zhou Q, Wang YJ, Liu J. Psychological stress alters microstructure of the mandibular condyle in rats. Physiol Behav. 2013;110-111:129-139. doi:10.1016/j. physbeh.2013.01.007

89. Gallotta S, Bruno V, Catapano S, Mobilio N, Ciacci C, Iovino P. High risk of temporomandibular disorder in irritable bowel syndrome: is there a correlation with greater illness severity? World $J$ Gastroenterol. 2017;23(1):103-109. doi:10.3748/wjg.v23. i1. 103

90. Green PG, Alvarez P, Gear RW, Mendoza D, Levine JD. Further validation of a model of fibromyalgia syndrome in the rat. J Pain. 2011;12(7):811-818. doi:10.1016/j.jpain.2011.01.006

91. Aaron LA, Burke MM, Buchwald D. Overlapping conditions among patients with chronic fatigue syndrome, fibromyalgia, and temporomandibular disorder. Arch Intern Med. 2000;160 (2):221-227. doi:10.1001/archinte.160.2.221

92. Sanders AE, Slade GD, Bair E, et al. General health status and incidence of first-onset temporomandibular disorder: the OPPERA Prospective Cohort Study. J Pain. 2013;14(12):T51T62. doi:10.1016/j.jpain.2013.06.001

93. Moreno-Fernandez AM, Jimenez-Castellanos E, IglesiasLinares A, Bueso-Madrid D, Fernandez-Rodriguez A, de Miguel M. Fibromyalgia syndrome and temporomandibular disorders with muscular pain. A review. Mod Rheumatol. 2017;27 (2):210-216. doi:10.1080/14397595.2016.1221788

94. Zhao YJ, Li JH, Hu B, et al. Extracellular signal-regulated kinase activation in the spinal cord contributes to visceral hypersensitivity induced by craniofacial injury followed by stress. Neurogastroenterol Motil. 2018;30(2):e13161. doi:10.1111/ nmo.13161
95. Ji Y, Hu B, Li J, Traub RJ. Opposing roles of estradiol and testosterone on stress-induced visceral hypersensitivity in rats. J Pain. 2018;19(7):764-776. doi:10.1016/j.jpain.2018.02.007

96. Ji Y, Hu B, Klontz C, et al. Peripheral mechanisms contribute to comorbid visceral hypersensitivity induced by preexisting orofacial pain and stress in female rats. Neurogastroenterol Motil. 2020;32(7):e13833. doi:10.1111/nmo.13833

97. Ayouni I, Chebbi R, Hela Z, Dhidah M. Comorbidity between fibromyalgia and temporomandibular disorders: a systematic review. Oral Surg Oral Med Oral Pathol. 2019;128(1):33-42. doi:10.1016/j.oooo.2019.02.023

98. Leblebici B, Pektas ZO, Ortancil O, Hurcan EC, Bagis S, Akman MN. Coexistence of fibromyalgia, temporomandibular disorder, and masticatory myofascial pain syndromes. Rheumatol Int. 2007;27(6):541-544. doi:10.1007/s00296-0060251-z

99. Fraga BP, Santos EB, Neto JPF, et al. Signs and symptoms of temporomandibular dysfunction in fibromyalgic patients. J Craniomaxillofac Surg. 2012;23(2):615-618. doi:10.1097/ SCS.0b013e31824cd81a

100. Franco AL, Goncalves DAG, Castanharo SM, Speciali JG, Bigal ME, Camparis CM. Migraine is the most prevalent primary headache in individuals with temporomandibular disorders. J Orofac Pain. 2010;24(3):287-292.

101. Goncalves DAG, Camparis CM, Franco AL, Fernandes G, Speciali JG, Bigal ME. How to investigate and treat: migraine in patients with temporomandibular disorders. Curr Pain Headache Rep. 2012;16(4):359-364. doi:10.1007/s11916-0120268-9

102. Romero-Reyes M, Akerman S, Nguyen E, et al. Spontaneous behavioral responses in the orofacial region: a model of trigeminal pain in mouse. Headache. 2013;53(1):137-151. doi:10.1111/ j.1526-4610.2012.02226.x
Journal of Pain Research

\section{Publish your work in this journal}

The Journal of Pain Research is an international, peer reviewed, open access, online journal that welcomes laboratory and clinical findings in the fields of pain research and the prevention and management of pain. Original research, reviews, symposium reports, hypothesis formation and commentaries are all considered for publication. The manuscript management system is completely online and includes a very quick and fair peer-review system, which is all easy to use. Visit http:// www.dovepress.com/testimonials.php to read real quotes from published authors. 